\title{
Alexandre Duquaire, Les illusions perdues du roman. L'abbé Prévost à l'épreuve du romanesque
}

\section{Franco Piva}

\section{(2) OpenEdition}

1 Journals

\section{Edizione digitale}

URL: http://journals.openedition.org/studifrancesi/9559

DOI: 10.4000/studifrancesi.9559

ISSN: 2421-5856

\section{Editore}

Rosenberg \& Sellier

\section{Edizione cartacea}

Data di pubblicazione: 1 décembre 2007

Paginazione: 664

ISSN: 0039-2944

\section{Notizia bibliografica digitale}

Franco Piva, «Alexandre Duquaire, Les illusions perdues du roman. L'abbé Prévost à l'épreuve du romanesque», Studi Francesi [Online], 153 (LI | III) | 2007, online dal 30 novembre 2015, consultato il 10 janvier 2021. URL: http://journals.openedition.org/studifrancesi/9559 ; DOI: https://doi.org/10.4000/ studifrancesi.9559

Questo documento è stato generato automaticamente il 10 janvier 2021.

\section{(c)}

Studi Francesi è distribuita con Licenza Creative Commons Attribuzione - Non commerciale - Non opere derivate 4.0 Internazionale. 


\title{
Alexandre Duquaire, Les illusions perdues du roman. L'abbé Prévost à l'épreuve du romanesque
}

\author{
Franco Piva
}

\section{NOTIZIA}

ALEXANDRE DUQUAIRE, Les illusions perdues du roman. L'abbé Prévost à l'épreuve du romanesque, Amsterdam-New York, NY, Rodopi, 2006 («Faux titre», 277), pp. 197.

1 Gli ultimi due romanzi dell'abbé Prévost non hanno mai incontrato molta fortuna, né presso i lettori, né presso i critici. Composti a distanza di 15 anni l'uno dall'altro, in un'epoca nella quale l'abbé Prévost pareva aver abbandonato la sua attività di romanziere per dedicarsi a una più onorevole, e lucrosa, attività di traduttore (specie dall'inglese) e di divulgatore, rimasti entrambi incompiuti, i Mémoires d'un honnête homme (1745) e il Monde moral (1760-1764), sono sembrati ai più, fin dal loro primo apparire, gli ultimi sfortunati, e tutto sommato fallimentari tentativi di uno scrittore ormai a corto di ispirazione.

2 L'analisi minuziosa alla quale Alexandre Duquaire li ha sottoposti nel suo lavoro, ha dimostrato che queste due opere sono, in realtà, assai più significative di quanto non si fosse supposto, o di quanto lo scarso successo da esse incontrato presso i lettori e presso i critici potesse lasciare ragionevolmente intravvedere. L'Autore fa, innanzitutto, notare come, seppure composte a distanza di una quindicina d'anni l'una dall'altra, queste due opere abbiano tra loro in comune molto di più di quanto non le separi, pur possedendo ciascuna una sua specificità, che Duquaire definisce via via; segno che entrambe obbediscono a una preoccupazione unica, ben presente, al di là delle differenze, al loro autore.

Dopo aver sottolineato le costanti e le varianti di queste due opere, Duquaire le mette in relazione con l'attività narrativa precedente di Prévost, per far vedere come esse si 
pongano in stretta relazione con le opere che le avevano precedute, a cominciare dalle grandi summae degli anni Trenta, i Mémoires et Aventures de l'homme de qualité e Cleveland ou le Philosohe anglais in primis, passando per le opere degli anni Quaranta (l'Histoire d'une Grecque moderne, la Jeunesse du Commadeur, i Mémoires de Montcal) senza trascurare un'opera più tardiva, ed apparentemente incongrua con la restante opera narrativa di Prévost, come i Voyages de Robert Lade. Questa lettura in prospettiva permette all'Autore di far vedere come l'opera narrativa di Prévost obbedisca a una costante, che consiste, proprio come indicato dal titolo del libro, in una progressiva, e cosciente presa di distanza dalle illusioni create dal romanesque, cui si contrappone una sempre più lucida e disincantata presa di coscienza della realtà, con le sue opacità, le sue zone d'ombra, $\mathrm{i}$ suoi lati oscuri, che Prévost impara a scrutare, a mano a mano che il tempo passa, con sempre maggiore attenzione, alla ricerca di quella verità che sta al di là, spesso, delle più belle apparenze, o che le «illusions [...] du romanesque» avevano contribuito a nascondere o a mostrare in altro modo.

Quella condotta da Alexandre Duquaire, è stata un'operazione molto utile non solo perché ha consentito di rivalutare due opere poco note ma anche, e forse soprattutto, perché ha aiutato il lettore a vedere anche il resto dell'opera narrativa di Prévost in un'ottica almeno in parte diversa e più ricca, nella sua problematicità, di quanto non fosse apparsa finora, portando a compimento quell'opera di revisione o di riconsiderazione alla quale avevano proceduto, alcuni anni orsono, gli studiosi che avevano fissato la loro attenzione sui romanzi degli anni Quaranta. L'analisi condotta da Alexandre Duquaire ha, d'altra parte, consentito di far emergere non solo la fedeltà di Prévost a quel genere narrativo che aveva fortemente e più di ogni altro forse, contribuito a rivalutare, ma anche l'originalità della sua posizione al riguardo, lineare e coerente pur in mezzo alle evoluzioni che il romanzo conobbe in quegli anni sia in Francia che altrove.

5 Assolutamente sottoscrivibili sono perciò, a nostro avviso, le conclusioni alle quali l'Autore perviene alla fine della sua lucida ricostruzione: «Relire les romans de l'abbé Prévost à partir de sa production ultime nous a permis d'apprécier l'évolution de son rapport au romanesque, et d'évaluer son attitude à l'égard des orientations nouvelles du roman, que consacre la décennie 1740. Trois éléments ont été ainsi observés, qui ont ponctué notre progression: la spécificité, dans l'œuvre prévostienne, des Mémoires d'un honnête homme et du Monde moral; la continuité, de 1728 à 1760, d'une critique du romanesque dont les modalités diffèrent; la distance de l'auteur à l'égard de ses contemporains, qu'ils appartiennent au courant libertin ou qu'ils souscrivent à la veine sentimentale. Bien davantage qu'un aboutissement, les deux derniers romans de Prévost nous ont donc apparu comme une confirmation, comme la marque d'une singularité irréductible, dont l'attitude ambivalente de l'écrivain envers les Lumières est le signe tangible». 